\title{
Developing Novel Photocatalytic Cementitious Permeable Pavements for Depollution of Contaminants and Impurities in Urban Cities
}

\author{
Kiran Tota-Maharaj ${ }^{1}$, Nichola Coleman ${ }^{2}$ \\ ${ }^{I}$ Department of Engineering Science, Faculty of Engineering \& Science, \\ University of Greenwich, Medway Campus, United Kingdom \\ ${ }^{2}$ Department of Pharmaceutical, Chemical \& Environmental Sciences, Faculty of Engineering \& Sciences, \\ University of Greenwich, Medway Campus, United Kingdom \\ E-mails: ${ }^{1}$ k.tota-maharaj@greenwich.ac.uk(correspondingauthor); ${ }^{2}$ n.coleman@greenwich.ac.uk
}

\begin{abstract}
Photocatalyst such as Titanium Dioxide $\left(\mathrm{TiO}_{2}\right)$ has been recently introduced as a nanoparticle into cementitious permeable pavements. Combining photocatalytic compounds within concrete permeable pavements can aid with depollution of several contaminants found in urban water streams and air impurities. This paper presents research carried out at the University of Greenwich, UK using photocatalytic concrete with varying percentages of $\mathrm{TiO}_{2}(0 \%, 1 \%$ and $5 \%)$ to assess the levels depollution which can be achieved. Concrete samples were testing against the degradation of 2, 4-Dichlorophenoxyacetic Acid, a harmful chemical found in herbicides. This advanced oxidation process can aid in the reduction of urban pollution from an air and water perspective, improving sustainability for urban cities. Self-cleaning benefits of photocatalytic concrete permeable pavements can be used to keep urban infrastructure cleaner and more aesthetically pleasing. Experimental tests were carried out on the characterisation of inorganics through X-Ray diffraction and Fourier Transform Infrared Spectroscopy to ensure that the structures of the concrete samples were not altered by addition of the nanoparticles (photocatalyst). Experimental results were compared to that found in previous literature and confirmed that the addition of $5 \% \mathrm{TiO}_{2}$ did not affect the structure of the concrete samples and can be a viable option used in urban infrastructure such as permeable pavements.
\end{abstract}

Keywords: permeable pavements, photocatalyst, Titanium Dioxide $\left(\mathrm{TiO}_{2}\right)$, water decontamination, atmospheric pollution.

Conference topic: Environmental Protection (Environmental Technologies \& Pollution Prevention).

\section{Introduction}

Photocatalytic concrete is one of the newest techniques used in engineered infrastructures which help to reduce high levels of pollution in urban areas. A catalyst, such as titanium dioxide $\left(\mathrm{TiO}_{2}\right)$, once added to the concrete mixture, reacts with sunlight, can efficiently achieves depollution. The reaction occurs on the surface of the concrete where the $\mathrm{TiO}_{2}$ particles come into contact with urban pollutants (Bartos, 2014). For the best results there should be a maximum number of $\mathrm{TiO}_{2}$ particles exposed on the surface without losing them to weathering or abrasion (Beeldens 2006). By roughing the surface of the concrete, a greater surface area can be created which generates higher number of photochemical reactions. Once the reaction has ended, the catalyst does not deplete and so this process is continuous throughout the structures lifetime. The photocatalytic concrete achieves depollution in both air and water and therefore can be used across a wide range of structures such as roads and buildings (Portland Cement Association 2014). Several reseaech projects have showed that in the presence of $\mathrm{TiO}_{2}$ for concrete structures can cause the degradation of Nitrogen Oxides (NOx) (Dalton et al. 2002; Sathish et al. 2005; Wang et al. 2009; Folli et al. 2012). There has been an increased amount of research into other possible pollutants which may also be photo-degraded.

Photocatalytic concrete can be used in new infrastructure as well as replacing old buildings and roads. Replacing existing infrastructure with photocatalytic concrete would be an expensive process but the environmental, physical and health benefits would make the improvement worthwhile and environmentally feasible. $\mathrm{TiO}_{2}$ has previously been used as a self-cleaning agent in cements (Chen et al. 2011). The use of this will result in savings being made in infrastructure as the concrete structures will not require frequent cleaning and maintenance of the structure will be reduced.

This project focuses on how titanium dioxide $\left(\mathrm{TiO}_{2}\right)$ in cement mixtures can potentially be used to remove a modelled contaminant 2,4-Dichlorophenoxyacetic Acid (2,4-D) - A herbicide used for controlling broadleaf weeds in agriculture which can cause sever illness if consumed (US EPA 2015). To verify whether photocatalytic concrete is successful for the detoixficaiton of urban water and air pollutants, samples of the developed concrete will have small amounts of the chosen contaminant placed on them. The effects of the presence of $\mathrm{TiO}_{2}$ on the contaminant will be measured. Twenty samples of photocatalytic concrete samples were manufactured under laboratory conditions. The samples consisted of $0 \%, 1 \%$ and $5 \%$ of $\mathrm{TiO}_{2}$ respectively. These experiments were designed to show the impact of $\mathrm{TiO}_{2}$ on the chosen contaminant and at what strengts of the photocatalyst will be need to achieve effective photodegradation. A 5\% concentration of $\mathrm{TiO}_{2}$ was selected as the maximum dosing range as the catalyst is expensive and would be unnecessary to have high percentages if degradation rates can be achived with lower concentrations. It is

(C) 2017 Kiran Tota-Maharaj, Nichola Coleman. Published by VGTU Press. This is an open-access article distributed under the terms of the Creative Commons Attribution (CC BY-NC 4.0) License, which permits unrestricted use, distribution, and reproduction in any medium, provided the original author and source are credited. 
expected that the $5 \%$ cement sample will show a greater rate of depletion compared to the $1 \%$ sample as it contains more catalytic and nanoparticles.

\section{Photocatalytic Concrete Pavements}

Photocatalytic concrete represents practical examples of research being used to develop ecofreindly products in achieving sustainability for the built environment and infrastructures. When photocatalyst are added to a material such as concrete it reacts with sunlight and pollutants and causes depollution. Strong sunlight or ultraviolet (UV) radiaition and solar light naturally causes organic material to decompose and with the use of photocatalysts, the process is accelerated (Concrete Society 2015). Research has shown that reactions which take place closer to the source cause greater depollution (Chen, Poon 2009; Shen et al. 2012).It has also been found that the speed of the reactions depend on the intensity of light, environmental conditions, adhesion of pollutants and amount of $\mathrm{TiO}_{2}$ (Beeldens 2006). If pavements and buildings are replaced with photocatalytic concrete then the photochemical reactions could be taking place contionusly, where pollutants are produced by cars and buildings.

There are further environmental benefits of photocatalytic concrete other than photodegradation of urban pollutants. Its light exterior colours reflects sunlight and solar fluxes which reduces heat absorption and reflection within urbanised zones, thus keeping the surrounding temperatures of buildings lower and causing a cooling effect of towns and cities (Tota-Maharaj, Scholz 2013). Photocatalytic concrete, other than the depollution of contaminants, provides further environmental benefits to cities. Its light exterior reflects sunlight which reduces heat absorption keeping the internal temperatures of buildings low and causes cooler cities. This results in less air conditioning being used and therefore a reduced amount of smog (World Resource Institute 2009). The white finish is also attractive which means it can be used within structures and because of its light finish; it lessens the need for internal lighting. Figure 1 below shows how the emissions and resources used in urban areas and photochemical distributed reations on the surface of concrete slabs. The presence of $\mathrm{TiO}_{2}$ in concrete can reduce both of air emissions (NOx) and urban water pollutants (nitrates, nitrities, ammonia and phosphates.
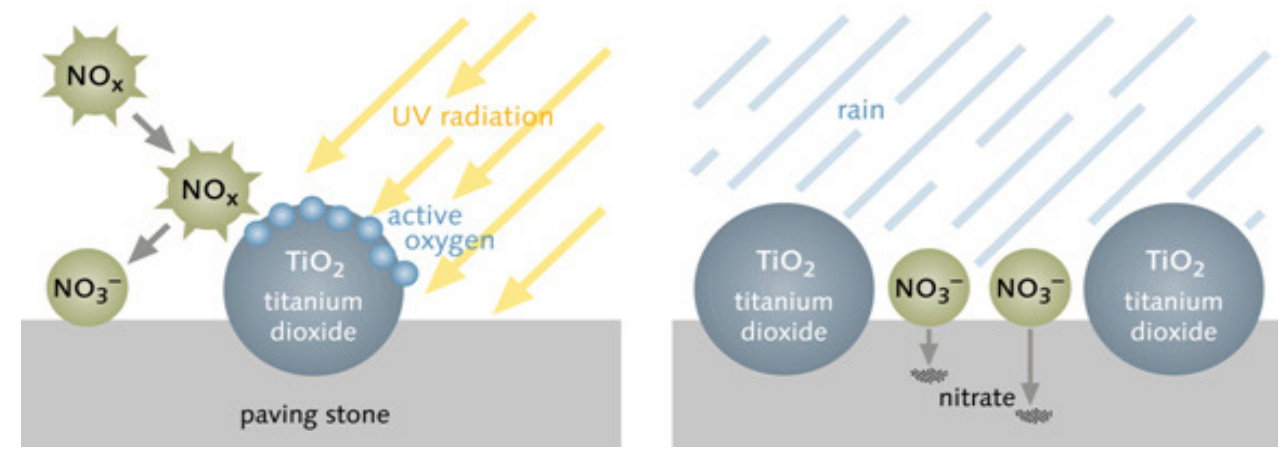

Fig. 1. Diagram of nitrous oxides (NOx) reduction process through the photo-catalytically active surfaces of the concrete that contains the photocatalytic cement (TioCem 2014)

\section{Modelled Pollutant 2,4-Dichlorophenoxyacetic Acid (2,4-D)}

The idea of $\mathrm{TiO}_{2}$ being used in concrete has already been developed. Nevertheless, there are several gaps in research and further investigation required to assess various types of pollutants that photocatalytic concrete structures (pavements) can degrade. Currently, the main pollutant that $\mathrm{TiO}_{2}$ has successfully removed is NOx. Another type of common pollutants which are released into the environment are pesticides and herbicides. The harmful chemicals used in the pesticides and herbicides eradicate weeds/small insects, but in larger quantities can become lethal to humans and animals. Herbicides and pesticides are commonly used in residential gardens as well as on a large scale for agricultural purposes. If in the presence of $\mathrm{TiO} 2$ within the concrete causes the degradation of harmful chemicals (herbicides and pesticides) then the products becomes more desirable and valuable to potential customers. The chemical and modelled pollutant to be tested in this study was 2,4-Dichlorophenoxyacetic Acid (2,4-D). This is a harmful chemical found in herbicides which has been used for agricultural purposes for over fifty years. 2,4-D is aimed at eliminating broad leaf weeds by being absorbed into the plant and accumulating at growing points which prevents the weed from further growth (Pesticide Action Network UK 1997). It is used in cereal crops where the growth of broad leaf weeds is extremely common. The World Health Organisation (WHO) categorises 2,4-D as a Class II (Moderately Hazardous) pollutant. 2,4-D has been found to cause serious health problems such as temporary loss of vision, bleeding and cancer when exposed for long periods of time (Alewu, Nosiri 2011). Due to its low absorption, traces of 2,4-D have been found in water sources and water treatment plants. This has led to it becoming tightly monitored with it potentially becoming restricted within the UK (Pesticide Action Network UK 1997). 


\section{Experimental Methodology}

\section{Developing the Photocatalytic Concrete Samples}

Three different types of cement mixture were prepared in the laboratory (University of Greenwich, Medway Campus), each containing a different percentages of $\mathrm{TiO}_{2}$ added to it $(0 \%, 1 \%$ and $5 \%)$. The methods for the production of all samples were the same with the lone variation on the amount of $\mathrm{TiO}_{2}$ added. The water-cement ratio used in the experiment was $0.45: 1$ (every $100 \mathrm{~g}$ of cement used, $45 \mathrm{~cm}^{3}$ of water was added). No aggregates were used in the cement mixture as the samples made were small and the experimental testing is not based on the strength of materials for photocatalytic concrete. Nanoparticles of $\mathrm{TiO}_{2}$ were used as they have a large surface area (compared to size) (Fig. 2a). A greater surface area of the $\mathrm{TiO}_{2}$ will be in contact with the pollutants resulting in larger photo-reduction rates. The containers that were used to set the cement mixtures were $5 \mathrm{~cm}$ in height and $3 \mathrm{~cm}$ in diameter. The cylindrical plastic containers were cut into five equal sections (Fig. 2b). Twenty discs of concerte samples were made each with varying percentages of $\mathrm{TiO}_{2}$. Each concrete sample disc was $1 \mathrm{~cm}$ in thickness. Multiple analyses of the concrete samples were carried out to achieve accurage results to reduce any possible anomalies within the experiments.

(a)

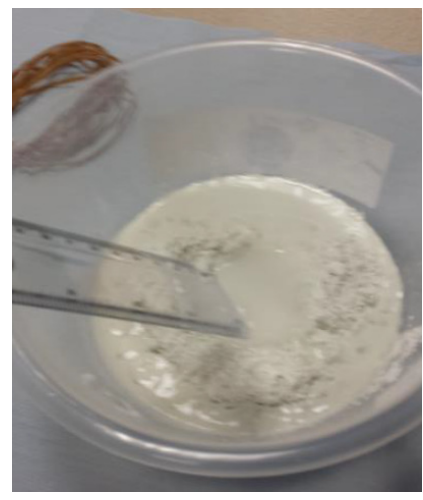

(b)

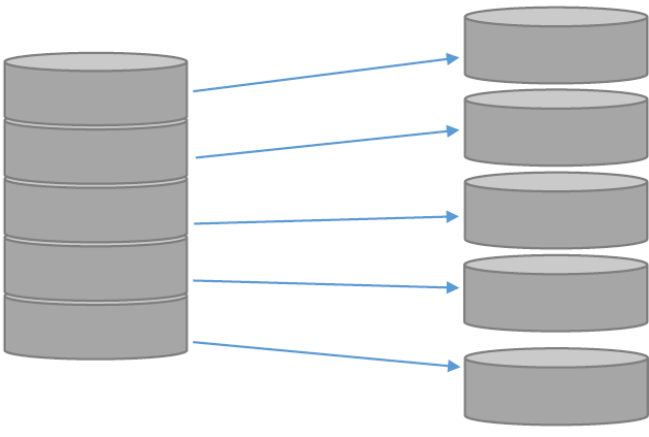

(c)

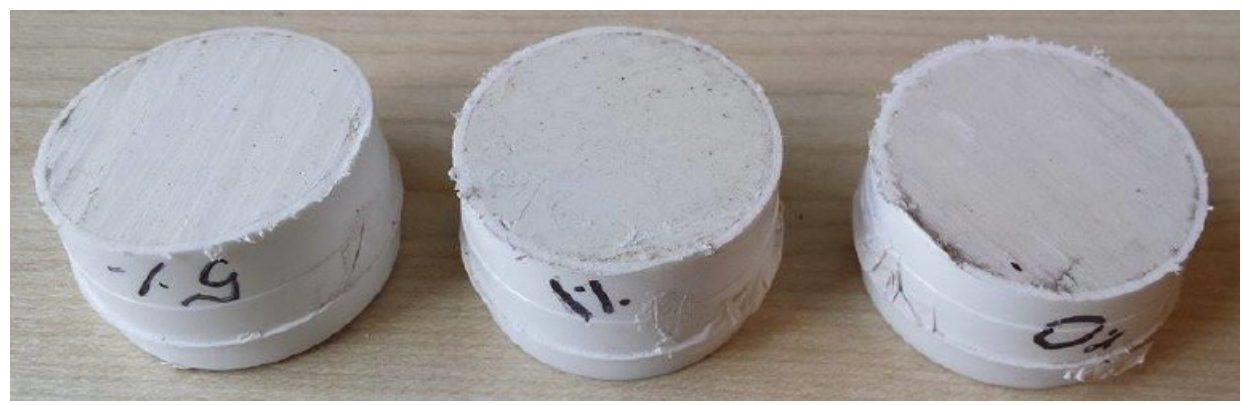

Fig. 2. (a) Formation of Concrete Discs, (b) Mixing the Cement with $\mathrm{TiO}_{2}$ (c) Self-Cleaning Concrete Samples

A mass of $400 \mathrm{~g}$ of White Portland Cement was weighed and placed into a re-sealable bag (making it easier to mix after $\mathrm{TiO}_{2}$ is added and preventing air entering). With respect to the $5 \%$ mixture, $20 \mathrm{~g}$ of $\mathrm{TiO}_{2}$ was weighed and added into the re-sealable bag with the cement. The bag was shaken several times for 10 minutes which allowed the particles to disperse, ensuring all $\mathrm{TiO}_{2}$ particles were distributed equally throughout the cement. The contents of the re-sealable bag was then transferred into a mixing container where $180 \mathrm{~cm}^{3}(45 \%$ of the initial $400 \mathrm{~g}$ of cement) was mixed with distilled water. The mixture was stirred rapidly for another 10 minutes which allowed the distilled water to evenly absorb the cement mixture. The containers were then filled with the cement mixture and tapped against the surface quickly for thirty seconds which allowed any air bubbles to rise to the surface. Lids were placed and sealed on all containers and were labelled with $0 \%, 1 \%$ and $5 \%$ respectively (Figure $2 \mathrm{c}$ ). The containers were left for a minimum of 30 days which allowed the concrete samples to set completely

\section{Testing characterisation of the inorganics X-Ray Diffraction (XRD)}

X-Ray diffraction (XRD) was used to determine the crystalline structure of the materials. The machine uses X-Rays and diffraction to measure the layers of crystals in the material (Loye 2015). The sample is converted into a powder form and placed onto a D8 Advanced X-Ray Difrractometer (Bruker, Germany) in theta-theta geometry reflection mode. $\mathrm{Cu} \mathrm{K \alpha}$ radiation was used at $40 \mathrm{kV}$ and $40 \mathrm{~mA}$ respectively. The data collection occured between $2-60^{\circ} 2 \theta$, step size of $0.02^{\circ}$ and a counting time of 1 second per step. 


\section{Fourier transform infrared spectroscopy (FTIR)}

Fourier Transform Infrared Spectroscopy (FTIR) is a process where a machine releases infrared radiation and passes it through the sample. Some of the radiation is absorbed by the sample and some transmitted (Thremo Nicolet Corporation 2001). The FTIR vibrates the bonds between the atoms of the sample. A detector then reads the resulting spectrum which represents the molecular absorption and transmission. This process creates a fingerprint for the material being tested (Thremo Nicolet Corporation 2001). The experiments were performed using a Perkin-Elmer Spectrum 2 with a University ATR attachment. Samples were scanned at a 4 wave-number resolution with a total accumulation of 16 scans.

\section{Measuring depollution levels of modeled contaimant}

Using the $\mathrm{TiO}_{2}$ in the cement created photocatalytic concrete samples, the depollution should occur when in presence of sunlight. As the experiment was carried out in a lab, a UV lamp and a solar lamp was used to activate the photochemical reactions to aid depollution of the modeled contaminant. The experimental setup is shown in Figures 3(a) and $3(b)$.
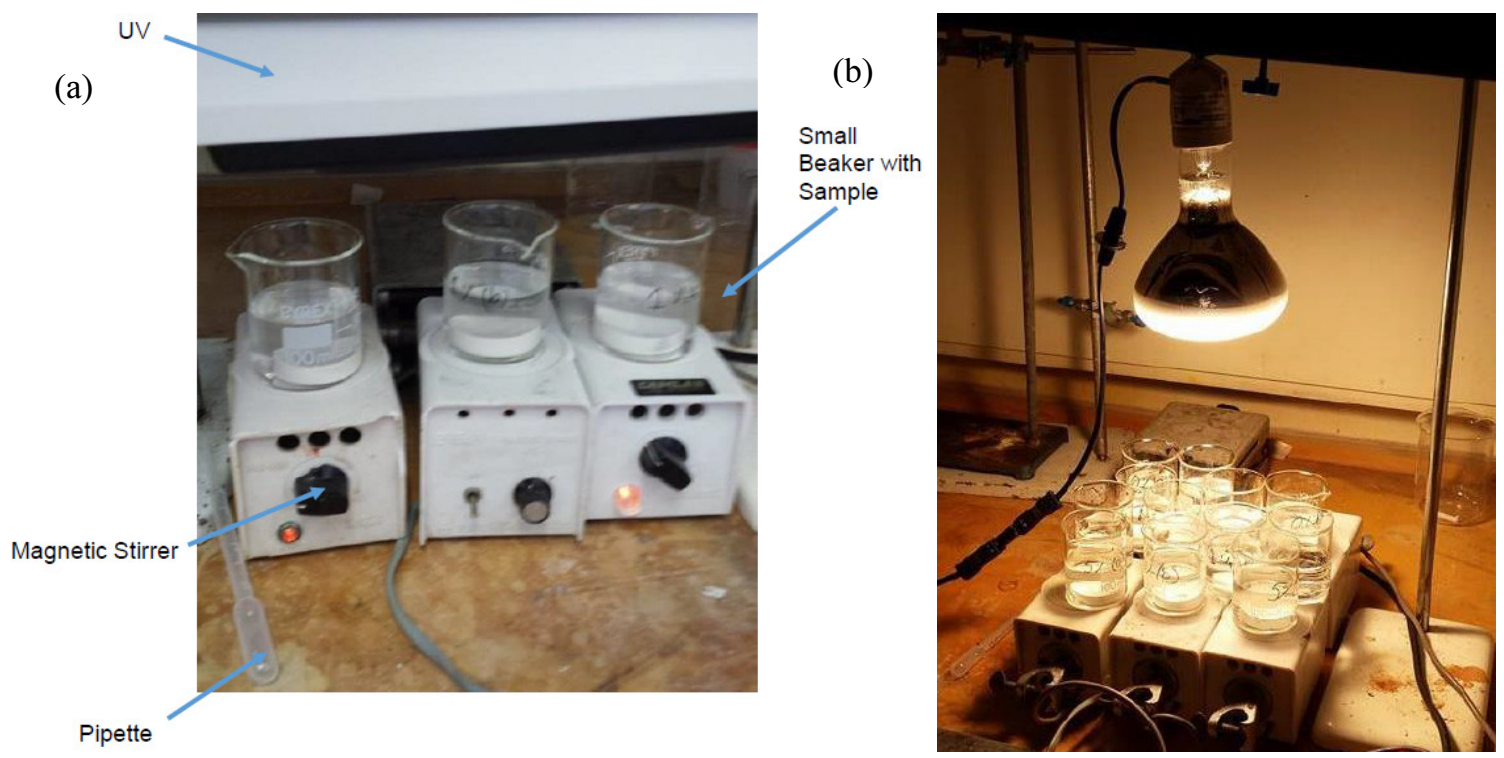

Fig. 3. (a) Ultraviolet (UV) Lamp experimental setup (b) Solar Lamp experimental setup

After the photocatalytic concrete samples were prepared by cutting the samples into cylinders approximately 1 $\mathrm{cm}$, each concrete sample was polished using ethanol and silicon carbide (polishing paper) to provide a smooth surface finish and remove any particles from the cutting process. Three samples of similar percentages of $\mathrm{TiO}_{2}$ concrete were placed in a small beaker and a 1 milli-molar solution of 2,4-D was added to each beaker respectively. A magnetic stirrer was placed in each beaker on top of the sample to ensure the modelled pollutant $(2,4-D)$ was fully mixed accessing all of the concrete samples. The samples were then placed under a UV lamp setup (Fig. 3(a)). This procedure was repeated for the Solar lamp setup (Fig. 3(b)). Recordings were taking at 15 minutes, 30 minutes and 60 minutes respectively. Using a pipette and filter, small volumes of the sample were taken and measured using a UV spectrometer which assessed whether the UV lamp increased the degradation rates of the 2,4-D. To assess whether the presence of $\mathrm{TiO}_{2}$ to the cement was effective, each experiment was repeated three times. Three beakers containing 2,4-D (controls) were placed under the UV lamp setup, and the Solar lamp setup. Theoretically, this result should remain constant when tested as no photocatalyst was added to these mixtures. Additionally, three more samples with the same percentages of $\mathrm{TiO}_{2}$ were placed in the dark to see whether photo-degradation and depollution of the contaminant still occurred. Ideally, the photocatalyst should react with sunlight or UV to cause depollution; therefore no changes are expected for the controls.

\section{Results and Discussion}

Figure 4 illustragtes the results for the XRD instruments for $0 \%, 1 \%$ and $5 \%$. The $\mathrm{x}$-axis is the angle $2 \theta$ which is the angle produced by the deflection of the X-Ray from the concrete samples. The $y$-axis is the measure of the intensity of the X-Rays detected. The results produced from the XRD test show that there are very little differences between the three different samples. The results peak at the same points throughout the graph, however, a difference in the height of the peaks can be seen. This suggests that the $\mathrm{TiO}_{2}$ did not have a major effect on the setting of the cement. The 
differences in height of the peaks $(0 \%, 1 \%$ and $5 \%)$ suggest a difference in the preparation of the samples which could be from the concrete being ground to different sizes.

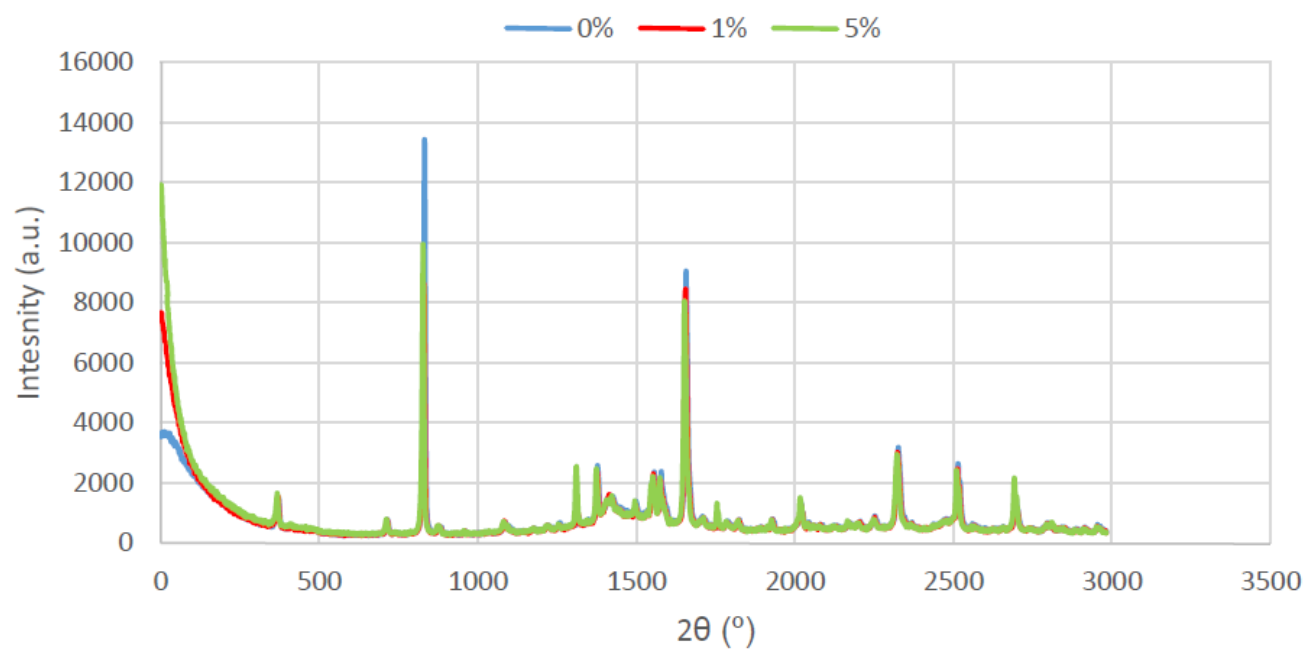

Fig. 4. XRD graphical results for $0 \%, 1 \%$ and $5 \% \mathrm{TiO}_{2}$ mixtures

The results from the test presented in Figure 6 shows four major components: Portlandite, Ettringite, Calcite and Larnite. These are all common phases found in set Portland cement (Ylmén et al. 2009). The results for the 1\% and $5 \%$ samples (not presented) also showed the same components which found (Portlandite, Ettringite, Calcite and Larnite). This suggests that the $\mathrm{TiO}_{2}$ has not reacted with the cement and the concrete structure has remained constant throughout. The graph shows the amount of Infrared which passed through the sample into the detector, shown on the $\mathrm{y}$-axis as the $\%$ transmittance. The $\mathrm{x}$-axis represents the wave number which is used for the assignment of the peaks. The experiments ran up to a wavenumber $4000 \mathrm{~cm}^{-1}$ but after $2000 \mathrm{~cm}^{-1}$ the results showed no substantial information from the samples. The experimental results generated by the XRD test produced graphical outputs for all samples $(0$ $\%, 1 \%$ and $5 \%$ ) had no signicant differences. This suggests that the addition of $\mathrm{TiO}_{2}$ to the cement mixture has not reacted with the cement or affected its setting. The $\mathrm{TiO}_{2}$ that was used in the cement mixture mainly consisted of rutile and a slight amount of anatase. Graphical outputs from the XRD test showed the crystalline structure of $\mathrm{TiO}_{2}$. $\mathrm{The}$ red colour represents the rutile whereas the blue colour represents the anatase (Fig. 7). The FTIR results for the $\mathrm{TiO}_{2}$ were also recorded but the graphs produced very limited information. This is because $\mathrm{TiO}_{2}$ is virtually transparent in the wavenumber region used. For these results to be seen, a much lower wavenumber would required.

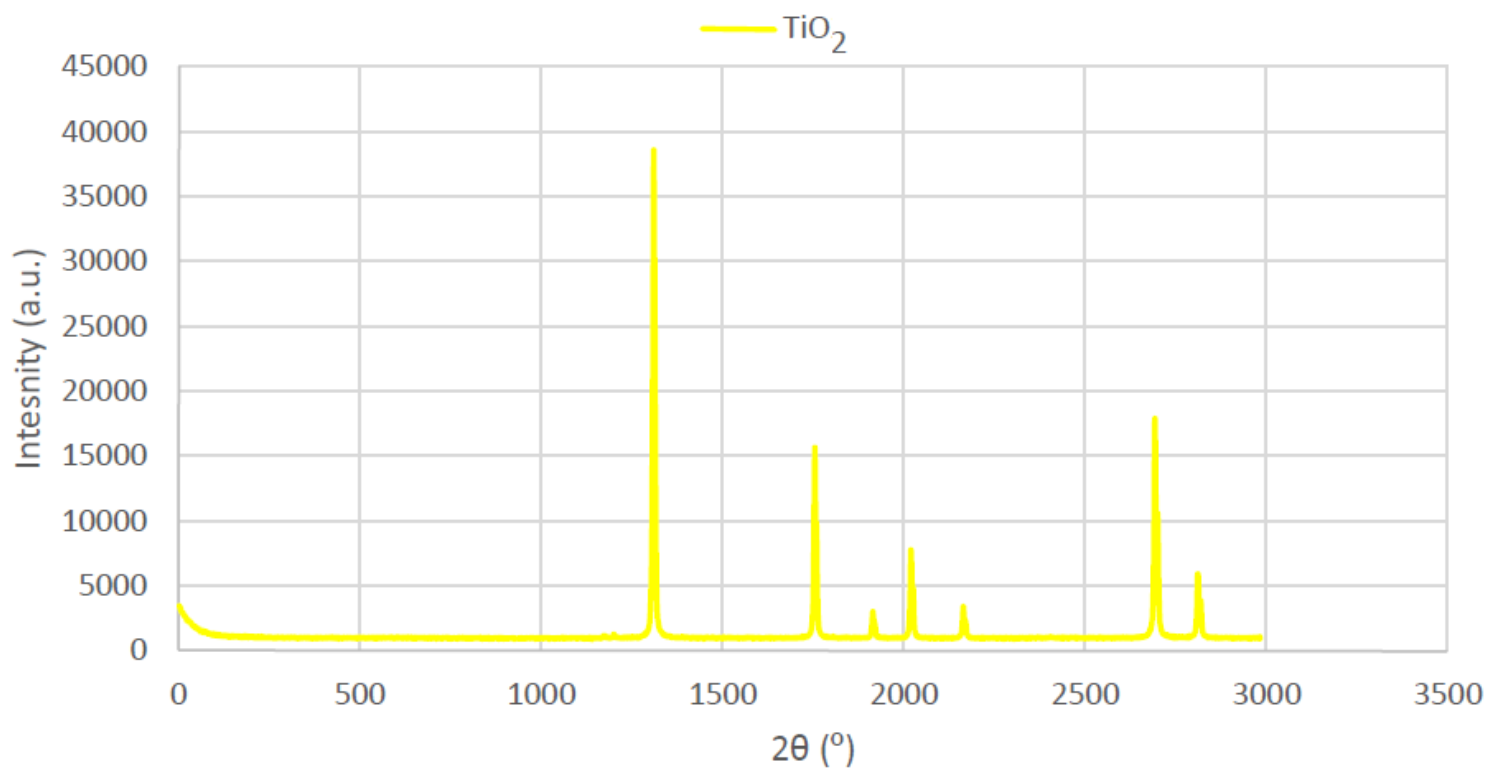

Fig. 5. Graphical results of $\mathrm{TiO}_{2}$ from XRD tes 


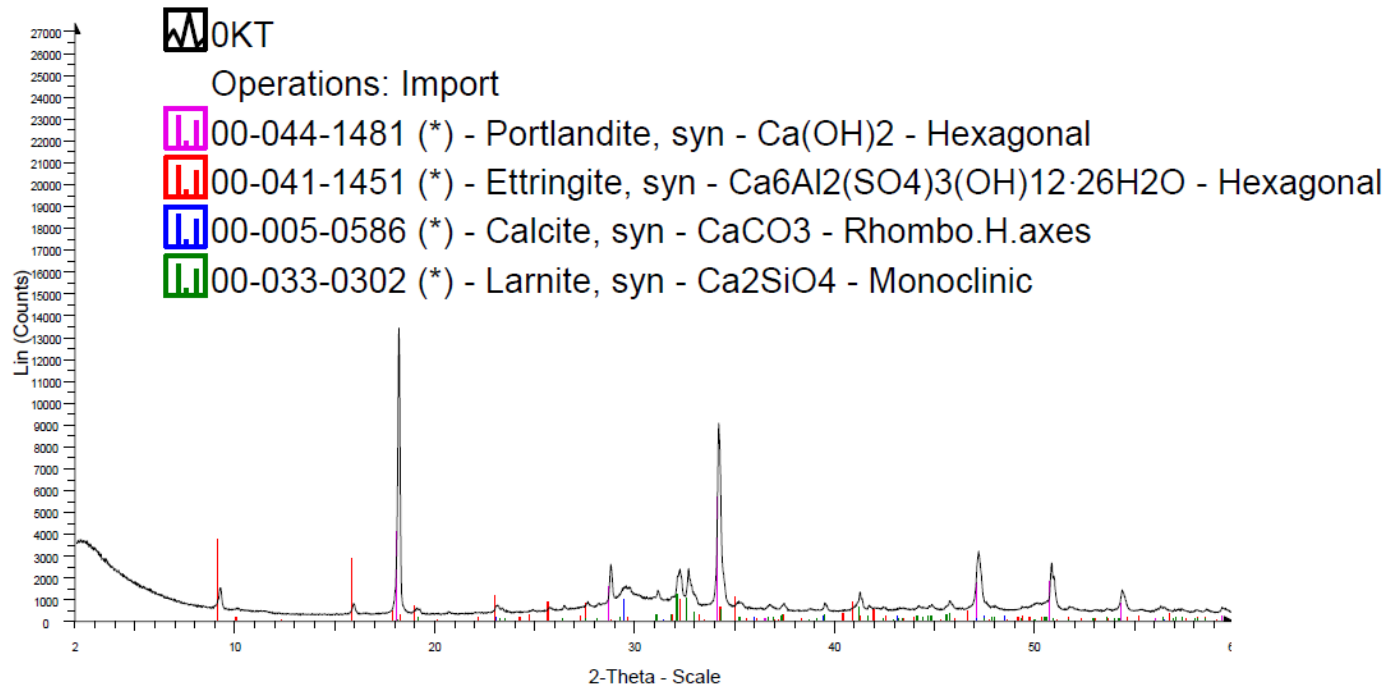

Fig. 6. Graphical results of XRD at $0 \%$ of $\mathrm{TiO}_{2}$

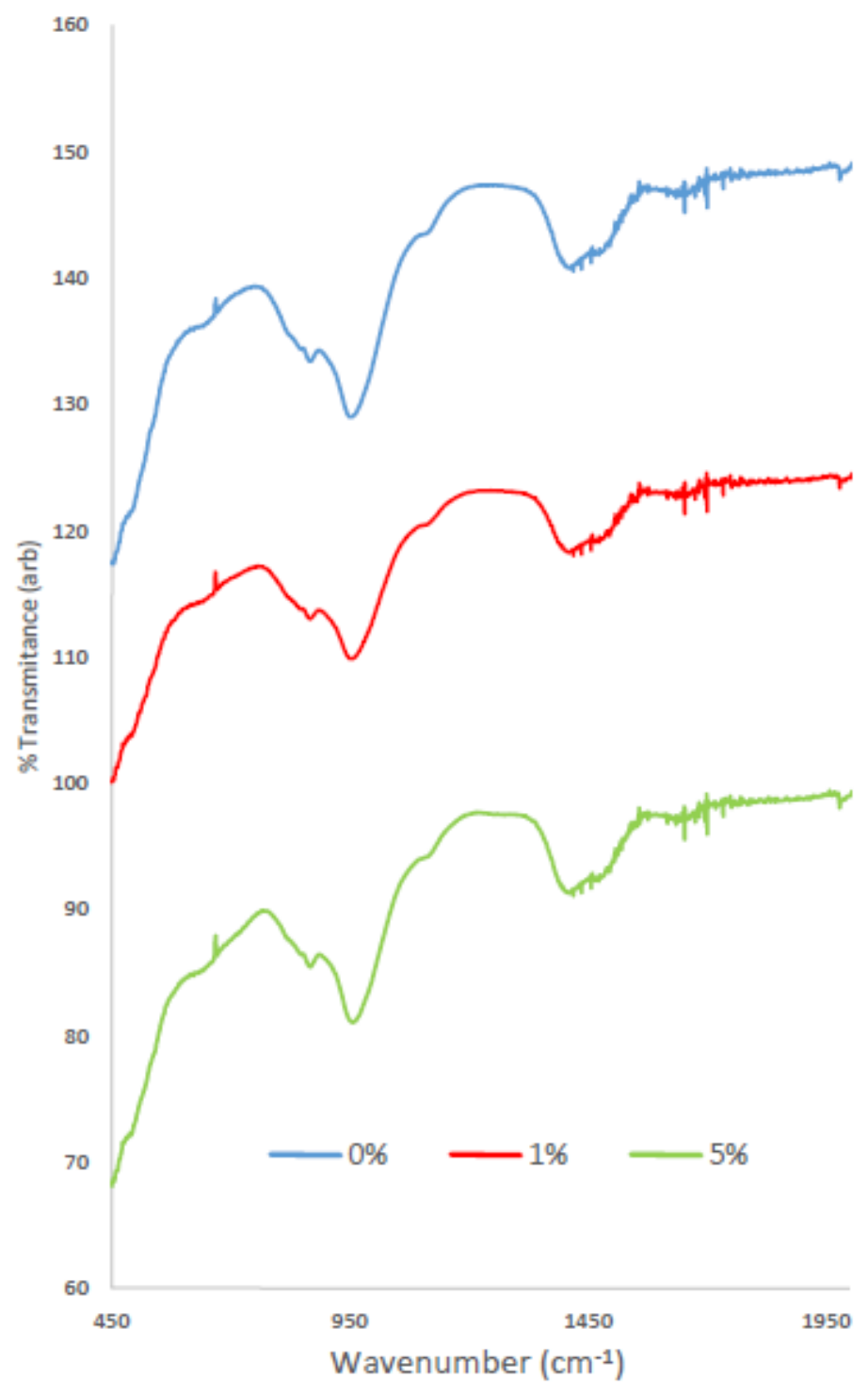

Fig. 7. Ftir $0 \%, 1 \%$ And $5 \%$ Results 

of contaminants and impurities in urban cities

From the graphs generated by the XRD tests (Figures 5 and 6) and the FTIR test (Figure 7), it can be noted that $\mathrm{TiO}_{2}$ samples mostly consisted of rutile. Luttrell et al. (2014) found that anatase has a higher photocatalytic activity when compared to rutile, which could have resulted in lower degradation rates of the modelled pollutant. The results from the testing for self-cleaning illustrates to some extent that $\mathrm{TiO}_{2}$ performed successfully when embedded into the concrete samples for depollution purposes. The photocatalytic concrete samples containing $5 \% \mathrm{TiO}_{2}$ remained whiter in appearance when compared to the other 2 samples; despite the small amounts of anatase depollution of the contaminant was still achieved. The results produced from the testing of the characterisation of inorganics, both XRD and FTIR, showed that the presence of $\mathrm{TiO}_{2}$ in the cement mixture did not affect the structure of the concrete when set.When these graphs are compared to the results obtained from the XRD for the cement samples, similarities were observed between peaks. This shows that the structure of the cement is consistent with the result found by Trezza (2007).

Table 1. Depollution rates of modelled pollutant $(2,4-\mathrm{D})(\mathrm{mmmol} / \mathrm{Litre})$ in presence of concrete samples with $\mathrm{TiO}_{2}$ at $1 \%$ with ultraviolet radiation (UV) lamp. ( ) - control results with no UV lamp

\begin{tabular}{|c|c|c|c|}
\hline Time (minutes) & $\begin{array}{c}\text { Sample A } \\
(\mathrm{mmol} / \text { Litre })\end{array}$ & $\begin{array}{c}\text { Sample B } \\
(\mathrm{mmol} / \text { Litre })\end{array}$ & $\begin{array}{c}\text { Sample C } \\
(\mathrm{mmol} / \mathrm{Litre})\end{array}$ \\
\hline 15 & $1.494(1.664)$ & $1.830(1.598)$ & $1.600(1.595)$ \\
\hline 30 & $1.172(1.584)$ & $1.691(1.592$ & $1.487(1.572)$ \\
\hline 60 & $1.053(1.271)$ & $1.091(1.290)$ & $1.301(1.477)$ \\
\hline
\end{tabular}

Once the results were recorded, it was observed that the 2,4-D was also degrading in the control samples as well (No UV lamp). This suggests that the photocatalytic concrete was also causing a depollution effect to 2, 4-D (Table 1). When comparing the results from 15 minutes to 30 minutes, as well as the final hour (60 minutes) there is an obvious reduction, suggesting that depollution levels have been achieved. After the results for 60 minutes were recorded, the photodegradation patterns did not continue.

Table 2. Depollution rates of modelled pollutant (2,4-D) (mmmol/Litre) in presence of concrete samples with $\mathrm{TiO}_{2}$ at $1 \%$ with Solar Lamp. ( ) - Control results with no solar lamp

\begin{tabular}{|c|c|c|c|}
\hline Time (minutes) & $\begin{array}{c}\text { Sample A } \\
(\mathrm{mmol} / \text { Litre })\end{array}$ & $\begin{array}{c}\text { Sample B } \\
(\mathrm{mmol} / \text { Litre })\end{array}$ & $\begin{array}{c}\text { Sample C } \\
(\mathrm{mmol} / \text { Litre })\end{array}$ \\
\hline 15 & $1.372(1.373)$ & $1.357(1.472)$ & $1.349(1.362)$ \\
\hline 30 & $1.362(1.299)$ & $1.378(1.385)$ & $1.064(1.306)$ \\
\hline 60 & $1.298(1.275)$ & $1.303(1.318)$ & $1.199(1.318)$ \\
\hline
\end{tabular}

From the results presented in Table 2, the Solar lamp also showed good levels of degrading the 2,4-D modelled contaminant. The degradation rates were slower for the controlled samples (no presence of Solar Lamp) when compared to the photocatalytic concrete samples in the presence of the solar lamp. There were no statistical differences ( $p$ $>0.05$ ) between the degradation rates of 2, 4-D for the UV lamp when compaired to the solar lamp with regards to concentrations of $1 \%$ and $5 \% \mathrm{TiO}_{2}$ within the concrete samples. This could have been a direct result of the low concentrations used throughout the experiment for the modelled pollutant.

\section{Conclusions and Outlook}

$\mathrm{TiO}_{2}$ in cementious permeable pavements can be an effective method of urban depollution. The research has shown that the applications of $\mathrm{TiO}_{2}$ in cement samples does not affect the structure of the concrete at $1 \%$ and $5 \%$ dosing which can be implemented in infrastructural engineering projects to achieve the breakdown of urban air and stormwater contaminants. An improvement in building materials can also be achieved by applying a thin layer of photocatalyst such as $\mathrm{TiO}_{2}$ onto the permeable paving blocks, making these permeable pavements more economical and eco-friendly. To achieve greater pollutant removal efficiencies higher concentrations of $\mathrm{TiO}_{2}$ in the anatase form needs to be applied. Future research outcomes will include using higher concentrations of 2,4-D, based on its unstability, it may provide more accurate results and demonstrated if the photocatalyst is effective in the degradation of the modelled pollutant (2, 4-D). The results can also fluctuate based on the distance of the concrete samples to the UV/Solar energy source. The closer or further away the concrete samples are the rate of depollutaion caused by $\mathrm{TiO}_{2}$ can vary. Further developments which can be carried out including evaluating different pollutants and various photocatalyst. Microbial pollutants such as E.coli or common herbicides such as Gluphosates can be tested against the presence of alternative photocatalyst (Zinc Oxide) and assessing the strength of concrete when embedded with photocatalyst and comparing other building materials. When $\mathrm{TiO}_{2}$ is added to concerete paving blocks, the strength of the concrete structure can be 

of contaminants and impurities in urban cities

altered reducing its practical applications, alternative building materials such as metals and glass can also be tested when embedded with photocatalyst to evaluate the depollutation rates throughout a wider range of building applications.

\section{Acknowledgements}

The authors would like to thank Katie Featherstone (Civil Engineering Undergraduate Student) at the University of Greenwich who contributed to this experimental project. The authors also gratefully acknowledge the technical staff and technicians from the Department of Pharmaceutical, Chemical \& Environmental Sciences and the Department of Engineering Science at the University of Greenwich.

\section{Funding}

University of Greenwich, Faculty of Engineering and Science, Research Excellence Framework (REF) Internal Grant for Wastewater Engineering and Water Reuse Projects.

\section{Contribution}

Dr. Kiran Tota-Maharaj (University of Greenwich) developed the conception and design of the project and also drafted the research article with support and collaboration from Dr. Nichola Coleman (University of Greenwich) who interpreted data outputs. Katie Featherstone (Civil Engineering Undergraduate Student, University of Greenwich) acquired datasets, conducted research experimetns on the project and also analysed data outputs for this research project.

\section{Disclosure statement}

The authors (Dr. Kiran Tota-Maharaj and Dr. Nichola Coleman) certify that they have No Affliations with or involvement in any organisation or entity with competing financial interest, professional or non-financial interest in the subject matter and materials discussed in this manuscript.

\section{References}

Alewu, B.; Nosiri, C. 2011. Pesticides and human health. Pesticides in the Modern World-Effects of Pesticides Exposure. InTech, 231-50.

Bartos, P. J. 2014. Photocatalytic concrete, Magazine of Concrete Research 1-2.

Beeldens, A. 2006. An environmental friendly solution for air purification and self-cleaning effect: the application of TiO2 as photocatalyst in concrete, in Proceedings of Transport Research Arena Europe-TRA, Göteborg, Sweden.

Chen, J.; Poon, C. S. 2009. Photocatalytic construction and building materials: from fundamentals to applications, Building and Environment 44(9): 1899-1906. https://doi.org/10.1016/j.buildenv.2009.01.002

Chen, J.; Kou, S. C.; Poon, C. S. 2011. Photocatalytic cement-based materials: comparison of nitrogen oxides and toluene removal potentials and evaluation of self-cleaning performance, Building and Environment 46(9): 1827-1833. https://doi.org/10.1016/j.buildenv.2011.03.004

Concrete Society. 2015. Self-Cleaning concrete [online], [cited 04 March 2015]. Available from Internet: $\mathrm{http}: / /$ www.concrete.org.uk/fingertips_nuggets.asp?cmd=display\&id=826

Dalton, J. S.; Janes, P. A.; Jones, N. G.; Nicholson, J. A.; Hallam, K. R.; Allen, G. C. 2002. Photocatalytic oxidation of NO x gases using TiO 2: a surface spectroscopic approach, Environmental Pollution 120(2):415-422. https://doi.org/10.1016/S02697491(02)00107-0

Folli, A.; Pade, C.; Hansen, T. B.; De Marco, T.; Macphee, D. E. 2012. $\mathrm{TiO}_{2}$ photocatalysis in cementitious systems: insights into self-cleaning and depollution chemistry, Cement and Concrete Research 42(3): 539-548. https://doi.org/10.1016/j.cemconres.2011.12.001

Loye, H. Z. 2015. X-Ray diffraction [online], [cited 04 March 2015]. Available from Internet: http://www.chem.sc.edu/faculty/zurloye/xrdtutorial_2013.pdf

Luttrell, T.; Halpegamage, S.; Tao, J.; Kramer, A.; Sutter, E.; Batzill, M. 2014. Why is anatase a better photocatalyst than rutile?Model studies on epitaxial $\mathrm{TiO}_{2}$ films, Scientific Reports 4(4043):1-8.

Pesticide Action Network UK. 1997. 2,4-D Factsheet, Pesticides News, 37: 20 [online], [cited 17 August 2016]. Available from Internet: http://www.pan-uk.org/factsheets/

Portland Cement Association. 2014. Self cleaning concrete [online], [cited 04 March 2016]. Available from Internet: $\mathrm{http} / / / \mathrm{www} . c e m e n t . o r g / c e m e n t-c o n c r e t e-b a s i c s /$ products/self-cleaning-concrete

Sathish, M.; Viswanathan, B.; Viswanath, R. P.; Gopinath, C. S. 2005. Synthesis, characterization, electronic structure, and photocatalytic activity of nitrogen-doped TiO2 nanocatalyst, Chemistry of Materials 17(25): 6349-6353. https://doi.org/10.1021/cm052047v 
Tota-Maharaj, K.; Coleman, N. 2017. Developing novel photocatalytic cementitious permeable pavements for depollution of contaminants and impurities in urban cities

Shen, S.; Burton, M.; Jobson, B.; Haselbach, L. 2012. Pervious concrete with titanium dioxide as a photocatalyst compound for a greener urban road environment, Construction and Building Materials 35: 874-883. https://doi.org/10.1016/j.conbuildmat.2012.04.097

Thremo Nicolet Corporation. 2001. Introduction to Fourier transform infrared spectrometry [online], [cited 07 January 2016]. Available from Internet: http://mmrc.caltech.edu/FTIR/FTIRintro.pdf

TioCem. 2014. Hanson TioCem [online], [cited 17 August 2016]. Available from Internet: http://heidelbergcement.com/NR/redonlyres

Tota-Maharaj, K.; Scholz, M. 2013. Combined permeable pavement and photocatalytic titanium dioxide oxidation system for urban run-off treatment and disinfection, Water and Environment Journal 27(3): 338-347.

Trezza, M. A. 2007. Hydration study of ordinary Portland cement in the presence of zinc ions, Materials Research 10(4): 331-334. https://doi.org/10.1590/S1516-14392007000400002

US EPA. 2015. Basic Information of 2,4-D in drinking water [online], [cited 07 January 2016]. Available from Internet: $\mathrm{http} / /$ water.epa.gov/drink/contaminants/basicinformation/2-4-d-2-4-dichlorophenoxyacetic-acid.cfm

Wang, J.; Tafen, D. N.; Lewis, J. P.; Hong, Z.; Manivannan, A.; Zhi, M.; Li, M.; Wu, N. 2009. Origin of photocatalytic activity of nitrogen-doped $\mathrm{TiO}_{2}$ nanobelts, Journal of the American Chemical Society 131(34): 12290-12297. https://doi.org/10.1021/ja903781h

World Resource Institute. 2009. Environmental Pollution [online], [cited 07 January 2016]. Available from the Internet: http://earthtrends.wri.org/updates/node/264

Ylmén, R.; Jäglid, U.; Steenari, B. M.; Panas, I. 2009. Early hydration and setting of Portland cement monitored by IR, SEM and Vicat techniques, Cement and Concrete Research 39(5): 433-439. https://doi.org/10.1016/j.cemconres.2009.01.017 